\title{
Clinical Predictors of Appropriate Implantable Cardioverter-Defibrillator Therapies in Primary Prevention: A Retrospective Study
}

\author{
Chiara Devecchi1,2, Eraldo Occhetta1, Vincenzo Alessandro Galiffa1, Gabriele Dell'Era1, \\ Andrea Magnani ${ }^{1}$, Francesco Rametta ${ }^{2}$, Paolo Nicola Marino' ${ }^{1}$ \\ ${ }^{1}$ AOU Maggiore della Carità, Novara, Italy \\ ${ }^{2}$ Presidio Ospedaliero S. Andrea, Vercelli, Italy \\ Email: devchiara@gmail.com
}

How to cite this paper: Devecchi, C., Occhetta, E., Galiffa, V.A., Dell'Era, G., Magnani, A., Rametta, F. and Marino, P.N. (2017) Clinical Predictors of Appropriate Implantable Cardioverter-Defibrillator Therapies in Primary Prevention: A Retrospective Study. World Journal of Cardiovascular Diseases, 7, 79-90.

https://doi.org/10.4236/wjcd.2017.73009

Received: January 28, 2017

Accepted: March 27, 2017

Published: March 30, 2017

Copyright $\odot 2017$ by authors and Scientific Research Publishing Inc. This work is licensed under the Creative Commons Attribution International License (CC BY 4.0).

http://creativecommons.org/licenses/by/4.0/

\begin{abstract}
Implantable cardioverter-defibrillator (ICD) in heart failure with reduced ejection fraction (EF) patients reduces risk for sudden cardiac death (SCD). Previous data suggest that the benefit of ICD therapy in real life may be lower than expected from the results of controlled studies and only about one-third of ICD patients receive appropriate therapies. Nevertheless, all ICD patients are at risk of perioperative complications and inappropriate shocks. We retrospectively studied 613 patients undergoing ICD for primary prevention in 2002-2015; we excluded inherited arrhythmogenic syndromes. Patients underwent 12-leads ECG, echocardiography, laboratory tests and quality of life questionnaire. We evaluated comorbidities, appropriate therapies, complications and all-cause mortality. Consecutive patients (age $67 \pm 10$ years, $81 \%$ males, 59\% ischaemic aetiology) were followed for $51 \pm 31$ months. 198 patients (32\%) received appropriate ICD therapy, 93 (15\%) had inappropriate shocks, $53(8 \%)$ had at least one complication (electrode dysfunction, infection and pocket related) and 191 (33\%) died. Multivariate analysis showed atrial fibrillation $(\mathrm{OR}=1.8, \mathrm{CI}=1.27-2.53 ; p<0.01)$, diabetes $(\mathrm{OR}=1.8, \mathrm{CI}$ $=1.27-2.53 ; p=0.041)$ and vasculopathy $(\mathrm{OR}=1.8, \mathrm{CI}=1.27-2.53 ; p=$ 0.031 ) as predictors of appropriate therapy. Logistic regression, considering atrial fibrillation, diabetes, vasculopathy, EF, NYHA class, left atrial diameter and natremia, identified SCD low risk group (probability < 0.1258 ). Ventricular arrhythmias necessitating ICD therapy are common, but complications and inappropriate therapies are frequent. Many parameters should be considered for a better selection of ICD candidates, to reduce ineffective implants. Our multifactorial score may eventually reduce about 10\% ICD implantation.
\end{abstract}


Keywords

ICD, Primary Prevention, Predictors, Appropriate Therapy, Complications

\section{Introduction}

Heart failure with reduced ejection fraction is associated with an increased risk of sudden cardiac death (SCD). Implantable cardioverter-defibrillators (ICD) have reduced mortality and become the standard of care for these patients, as recommended by current international guidelines [1] [2]. In a pooled analysis of 10 different studies on primary preventive defibrillators in patients with heart failure, all-cause mortality with ICD therapy was reduced about by $7.9 \%$ compared with optimal medical treatment only [3]. All ICD patients are at an increased risk of perioperative complications, inappropriate shocks, and secondary arrhythmias [4]. The reported complication rates vary in different studies, but in a recent review of 11 well-known randomized ICD studies, the overall lead dislodgement rate was $1.8 \%$ [5]. A much higher complication rate was reported in a real-life survey of 440 ICD patients in Germany, where $31 \%$ of the patients experienced some type of complication [6].

Previous studies have tried to identify predictors of appropriate ICD therapies, including atrial fibrillation (AF) [7] [8], renal dysfunction [9], advanced New York Heart Association (NYHA) class [10], age [10], gender [11] [12] and parameters of electrical instability or arrhythmic substrate [13]. However, all those trials included different patient populations, so it is very difficult to draw conclusions for clinical decision. The aim of this study was to investigate, in reallife, the net benefit of primary preventive defibrillators as regards the incidence of appropriate ICD therapies, inappropriate shocks, complications, and identify clinical parameters and comorbidities associated with appropriated ICD therapies for a better selection of ICD candidates.

\section{Materials and Methods}

We scrutinized 875 consecutive patients undergoing ICD implantation from June 2002 to May 2015 in Cardiology Department (Novara); we excluded patients with a history of previous sustained ventricular arrhythmias and cardiac arrest (209 patients), arrhytmogenic syndrome as Brugada and Long QT syndromes, arrhythmogenic right ventricular dysplasia and hypertrophic cardiomyopathy (53 patients). We enrolled 613 consecutive patients receiving an ICD for primary prevention of SCD; all patients underwent ICD implantation according to current international guidelines [1] [2], defined as LVEF $\leq 35 \%$, NYHA class II-IV, optimal medical therapy, life expectancy > 1-year; cardiac resynchronization therapy was performed if indicated. We evaluated in ischemic and non ischemic cardiomyopathy appropriate and inappropriate ICD therapies (Figure 1). All patients underwent before the ICD implantation 12-leads elec- 


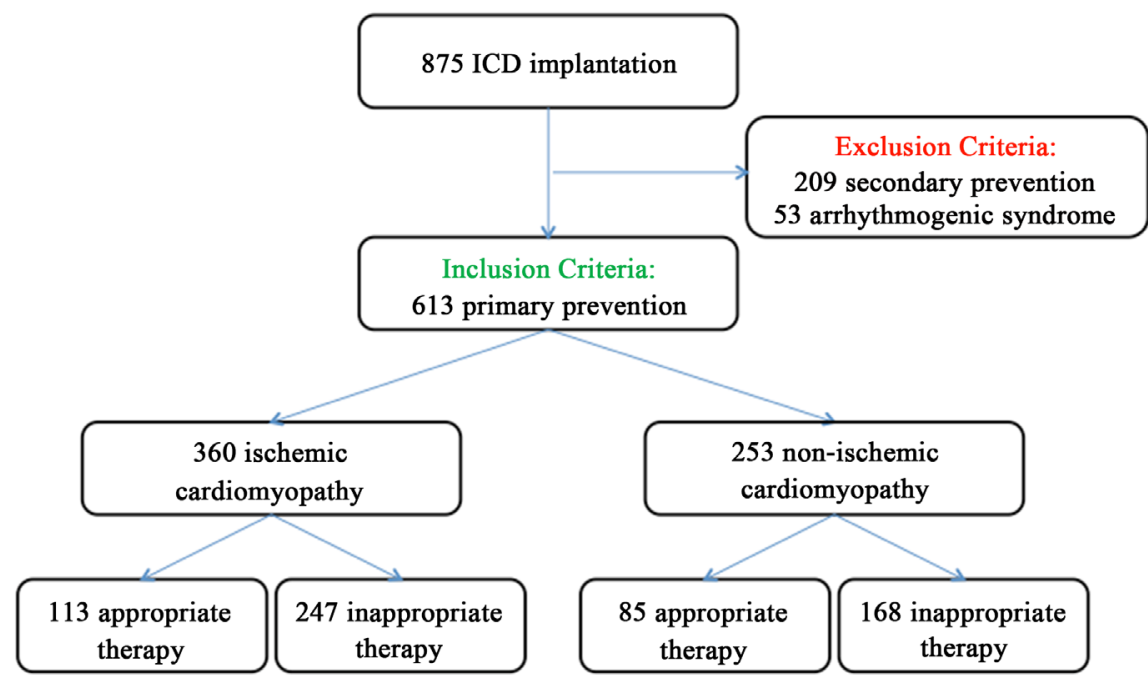

Figure 1. Study design and appropriate therapy in ischemic and non ischemic cardiomyopathy.

trocardiography, transthoracic echocardiography, laboratory test and evaluation of quality of life and NYHA class.

Transthoracic echocardiography data were acquired using the available system (Vivid-7 and Vivid-9 General Electric Vingmed, Milwaukee, USA). Left ventricular end-diastolic and end-systolic volumes were assessed from the apical twoand four-chamber images, and left ventricle ejection fraction (LV-EF) was calculated according to the monoplane or biplane Simpson method; diastolic function, left ventricle and left atrial M-mode parameters, color-Doppler parameter were evaluated according to guidelines [14] [15] [16].

Quality of life and NYHA class were evaluated by questionnaire (Kansas [17] and Minnesota living with heart failure questionnaire [18]) and functional test (6 minutes walking test [19]).

All patients' medical records were scrutinized in order to verify the data from the ICD registry regarding indications and to evaluate the patients' morbidity before implantations. Cardiovascular risk factors and comorbidities (hypertension, diabetes, renal disfunction, anemia, pulmonary disease) were considered according to international cut offs. Atrial fibrillation was defined as any known episode of atrial fibrillation and classified as paroxysmal, persistent and permanent. All patients received antibiotic prophylaxis before the ICD implantation. ICDs were programmed according to the attendant physician's preferences, and all patients had antitachycardia pacing (ATP) programmed before shock therapy. The ventricular tachycardia (VT) zones were normally programmed from $150 / 160$ to $180 / 190$ beats per minutes, and the ventricular fibrillation (VF) zone > $180 / 190$ beats per minute. In the medical records we evaluated the presence of appropriate therapies such as ATPs or shocks. If an arrhythmia episode required ICD discharge after unsuccessful ATP therapy, it was classified as shock treatment in the analyses. The therapy was classified as appropriate or inappropriate according to the attending physician's medical notes. Appropriate therapy was 
defined as ventricular arrhythmias correctly sensed and treated by the devices. All complications related to defibrillator therapy were analyzed. We investigated both procedure-related complications and remote complications such as electrode problems, infections, and inappropriate therapies. Electrode problems were defined as unacceptably high pacing thresholds, low sensing amplitude, or diaphragmatic stimulation that could not be resolved with electronic re-programming. During follow up all cause mortality and cardiovascular mortality were considered.

Continuous variables are reported as mean \pm standard deviation and categorical variables as frequencies. Continuous variables were compared using Student's t-test and ANOVA, while categorical variables were compared using $\chi^{2}$ test and Fisher's exact test. To determine the predictive factors of device therapy, univariate and multivariate analyses were performed. Variables with a P-value of $\leq 0.1$ in univariate analysis were then included in the multivariate regression analysis for the determination of odds ratio (OR) and its $95 \%$ confidence interval (CI). A P-value of $\leq 0.05$ was considered statistically significant. Survival and event-free rates from ICD intervention were calculated and depicted with the Kaplan-Meier method. All these analyses were performed using SPSS v20.0 (SPSS Inc., Chicago, IL, USA). Logistic regression, using Akaike Information Criterion [20], and ROC curves were performed using R 3.3.0 (R Development Core Team).

\section{Results}

Patient data at baseline are summarized in Table 1. Patients had a mean age of $67.4 \pm 10.1$ years, $80.9 \%$ male, $19.1 \%$ female, with LV-EF of $26 \% \pm 8.4 \%$, congestive heart failure of NYHA II (52.2\%), due to ischemic aetiology ( $\mathrm{n}=360$, $58.7 \%)$, valvular aetiology $(\mathrm{n}=57,9.3 \%)$ or idiopathic cardiomyopathy $(\mathrm{n}=196$, $32 \%)$; atrial fibrillation $(\mathrm{n}=271,44.2 \%)$ and cardiac resynchronization therapy $(\mathrm{n}=300,48.9 \%)$ were common. Mean follow up was $50.7 \pm 31.5$ months, 41 (6.7\%) patients were lost at follow up and $4(0.7 \%)$ underwent heart transplantation. There were no significant differences in comorbidities between male and female.

During follow-up 198 patients (32\%) received appropriate ICD therapy, 93 patients (15\%) had inappropriate shocks, 53 patients (8\%) had at least one complication (electrode dysfunction, infection and pocket related) and 191 patients (33\%) died. The annual rate of patients who received their first appropriate ICD interventions was $7.5 \%$. The median time to first appropriate therapy after ICD implantation was 24 months (range 1 - 107). Differences in baseline characteristic between patients with and without appropriate ICD therapy are listed in $\mathrm{Ta}$ ble 2.

In patients who received appropriate therapy were present significantly lower level of sodium $(137.8 \pm 3.7 \mathrm{ml}$ vs $138.9 \pm 3.5 \mathrm{ml} ; p<0.01)$ and atrial fibrillation ( $\mathrm{n}=107,54 \%$ vs $\mathrm{n}=164,39.5 \% ; p=0.001$ ). Indeed, among echo parameters, they had significantly reduced ejection fraction $(25 \% \pm 6.5$ vs $26.5 \pm 9.1 ; p=$ 
Table 1. Baseline characteristics before implantation.

\begin{tabular}{|c|c|}
\hline & Baseline \\
\hline \multicolumn{2}{|l|}{ Age and gender } \\
\hline Mean age (years) & $67.4 \pm 10.1$ \\
\hline Male (\%) & $496(80.9)$ \\
\hline \multicolumn{2}{|l|}{ Aetiology } \\
\hline Ischemic (\%) & $360(58.7)$ \\
\hline Previously AMI (\%) & $313(51.1)$ \\
\hline Previous coronary bypass surgery (\%) & $181(29.5)$ \\
\hline Valvular aetiology (\%) & $57(9.3)$ \\
\hline Idiopathic cardiomyopathy (\%) & $196(32)$ \\
\hline Atrial fibrillation (\%) & $271(44.2)$ \\
\hline \multicolumn{2}{|l|}{ Functional class } \\
\hline NYHA II (\%) & $354(57.7)$ \\
\hline NYHA III (\%) & $242(39.5)$ \\
\hline NYHA IV (\%) & $17(2.8)$ \\
\hline \multicolumn{2}{|l|}{ ECG and Echo parameters } \\
\hline QRS > 120 msec (\%) & $319(52)$ \\
\hline Left bundle-branch block (\%) & $292(47.6)$ \\
\hline CRT-D (\%) & $300(48.9)$ \\
\hline Mean LVEF (\%) & $26.0 \pm 8.4$ \\
\hline LV end diastolic volume (ml) & $189.3 \pm 59.3$ \\
\hline LV end systolic volume (ml) & $141.6 \pm 51.4$ \\
\hline $\mathrm{LV}$ end diastolic diameter (mm) & $67.1 \pm 8.4$ \\
\hline LV end systolic diameter (mm) & $54.8 \pm 9.2$ \\
\hline LA diameter $(\mathrm{mm})$ & $47.5 \pm 7.7$ \\
\hline \multicolumn{2}{|l|}{ Comorbility } \\
\hline Hypertension (\%) & $404(65.9)$ \\
\hline Diabetes (\%) & $163(26.6)$ \\
\hline Pulmonary disease (\%) & $138(22.5)$ \\
\hline Kidney disease (\%) & $133(21.7)$ \\
\hline Creatinine (mg/dl) & $1.3 \pm 0.6$ \\
\hline $\mathrm{Na}(\mathrm{mEq} / \mathrm{l})$ & $138.5 \pm 3.6$ \\
\hline $\mathrm{K}(\mathrm{mEq} / \mathrm{l})$ & $4.1 \pm 0.4$ \\
\hline Anemia (\%) & $122(19.9)$ \\
\hline Haemoglobin (g/dl) & $13.3 \pm 1.6$ \\
\hline Vasculopathy (\%) & $135(22)$ \\
\hline Beta-blocker therapy (\%) & $489(79.8)$ \\
\hline Amiodarone (\%) & $168(27.4)$ \\
\hline
\end{tabular}


Table 2. Difference in baseline characteristic between patients with and without appropriate ICD therapy.

\begin{tabular}{|c|c|c|c|}
\hline & $\begin{array}{c}\text { Appropriate } \\
\text { therapy } \\
(n=198)\end{array}$ & $\begin{array}{c}\text { Without appropriate } \\
\text { therapy } \\
(n=415)\end{array}$ & $P$-value \\
\hline Mean age (years) & $66.84 \pm 9.6$ & $67.6 \pm 10.3$ & 0.369 \\
\hline Male (\%) & $168(84.8)$ & $328(79.0)$ & 0.087 \\
\hline Hypertension (\%) & $125(63.1)$ & $279(67.2)$ & 0.317 \\
\hline Diabetes (\%) & $43(21.7)$ & $120(28.9)$ & 0.059 \\
\hline Pulmonary disease (\%) & $49(24.7)$ & $89(21.4)$ & 0.360 \\
\hline Kidney disease (\%) & $35(17.7)$ & $98(23.6)$ & 0.095 \\
\hline $\mathrm{K}(\mathrm{mEq} / \mathrm{L})$ & $4.1 \pm 0.4$ & $4.1 \pm 0.4$ & 0.775 \\
\hline $\mathrm{Na}(\mathrm{mEq} / \mathrm{L})$ & $137.8 \pm 3.7$ & $138.9 \pm 3.5$ & 0.001 \\
\hline Anemia (\%) & $32(16.2)$ & $90(21.7)$ & 0.109 \\
\hline Vasculopathy (\%) & $52(26.3)$ & $83(20.0)$ & 0.080 \\
\hline Ischemic aetiology (\%) & $113(57.1)$ & $247(59.5)$ & 0.565 \\
\hline Previously AMI (\%) & $98(49.5)$ & $215(51.8)$ & 0.592 \\
\hline Previous coronary bypass surgery (\%) & $65(32.8)$ & $116(28.0)$ & 0.216 \\
\hline Atrial fibrillation (\%) & $107(54.0)$ & $164(39.5)$ & 0.001 \\
\hline NYHA III-IV (\%) & $79(39.9)$ & $180(43.4)$ & 0.415 \\
\hline QRS > 120 msec (\%) & $106(53.5)$ & $213(51.3)$ & 0.609 \\
\hline Left bundle-branch block (\%) & $97(49.0)$ & $195(47.0)$ & 0.643 \\
\hline CRT-D (\%) & $93(47.0)$ & $207(49.9)$ & 0.500 \\
\hline Mean LVEF (\%) & $25.0 \pm 6.5$ & $26.5 \pm 9.1$ & 0.035 \\
\hline LV end diastolic volume (ml) & $195.1 \pm 59.0$ & $186.6 \pm 59.3$ & 0.096 \\
\hline LV end systolic volume (ml) & $147.4 \pm 50.2$ & $138.8 \pm 51.7$ & 0.051 \\
\hline $\mathrm{LV}$ end diastolic diameter $(\mathrm{mm})$ & $67.6 \pm 9.1$ & $66.8 \pm 8.1$ & 0.240 \\
\hline LV end systolic diameter (mm) & $56.1 \pm 9.5$ & $54.1 \pm 9.0$ & 0.015 \\
\hline LA diameter (mm) & $48.7 \pm 8.0$ & $46.9 \pm 7.5$ & 0.007 \\
\hline Beta-blocker therapy (\%) & $155(78.3)$ & $334(80.5)$ & 0.526 \\
\hline Amiodarone (\%) & $57(28.8)$ & $111(26.7)$ & 0.596 \\
\hline
\end{tabular}

0.035), higher LV end systolic volume and diameter (respectively $147.4 \pm 50.2$ $\mathrm{mm}$ vs $138.8 \pm 51.7 \mathrm{~mm} ; p=0.051$ and $56.1 \pm 9.5 \mathrm{~mm}$ vs $54.1 \pm 9.0 \mathrm{~mm} ; p=$ $0.015)$ and higher left atrial diameter $(48.7 \pm 8.0 \mathrm{~mm}$ vs $46.9 \pm 7.5 \mathrm{~mm} ; p=$ 0.007).

A stepwise multivariate analysis was performed and 3 significant factors were correlated to appropriate therapy: atrial fibrillation $(\mathrm{OR}=1.8, \mathrm{CI}=1.27-2.53 ; p$ $<0.01)$, diabetes $(\mathrm{OR}=1.8, \mathrm{CI}=1.27-2.53 ; p=0.041)$ and vasculopathy $(\mathrm{OR}=$ $1.8, \mathrm{CI}=1.27-2.53 ; p=0.031)$.

Finally, we tried to identify a predictive score of appropriate therapy based on 
clinical parameters. We used logistic regression, including all variables as covariates and we screened all possible models including almost one of these. We found 220 models and to determine the best we used Akaike Information Criterion. The best model considered seven parameters that were strongly associated with appropriate therapy (atrial fibrillation, diabetes, vasculopathy, LVEF, NYHA class, left atrial diameter and natremia) and identified a difference in SCD risk probability statistically significant between patients with (APP+) and without (APP-) appropriate therapy. Probability $<0.1872$ corresponded to 5th percentile of group receiving appropriate therapy; using this cut-off we identified a population at low risk of ICD treatment (only 10/102 patients; of these 10 patient 8 received only one ATP therapy and 2 patients received only one shock on sustained TV). Probability $<0.1258$ corresponded to lower value of group receiving appropriate therapy; using this cut-off we identified patients who never received appropriate therapy (65 patients) (Figure 2).

The total number of patients who had complications, including inappropriate shock, during follow-up was 138 (22.5\%). Of these, 93 patients (15.2\%) received inappropriate shock, in most cases on sopraventricular tachiarrhythmia (prevalent atrial fibrillation); 53 patients (8.6\%) had complications that required reintervention (electrode dysfunction, infection and pocket related). The types of complications are listed in Table 3; in summary the most common problems were inappropriate shocks $(\mathrm{n}=93,15.2 \%)$ and dislocation or dysfunction of the ICD electrode $(\mathrm{n}=33,5.4 \%)$.

Forty one of 613 patients (6.7\%) were lost during follow up; 191 of 572 patients (33.4\%) died during follow-up. 73 of 191 patients (38.2\%) received an appropriate therapy on a ventricular arrhythmia. The median time from first appropriate therapy to death was 20 months (range 1 - 105).

Cardiovascular mortality was observed in 68 patients (11.9\%), 87 patients (15.2\%) died for non cardiovascular reasons and we had no data about 36 patients (6.3\%). All causes mortality are presented in Figure 3.

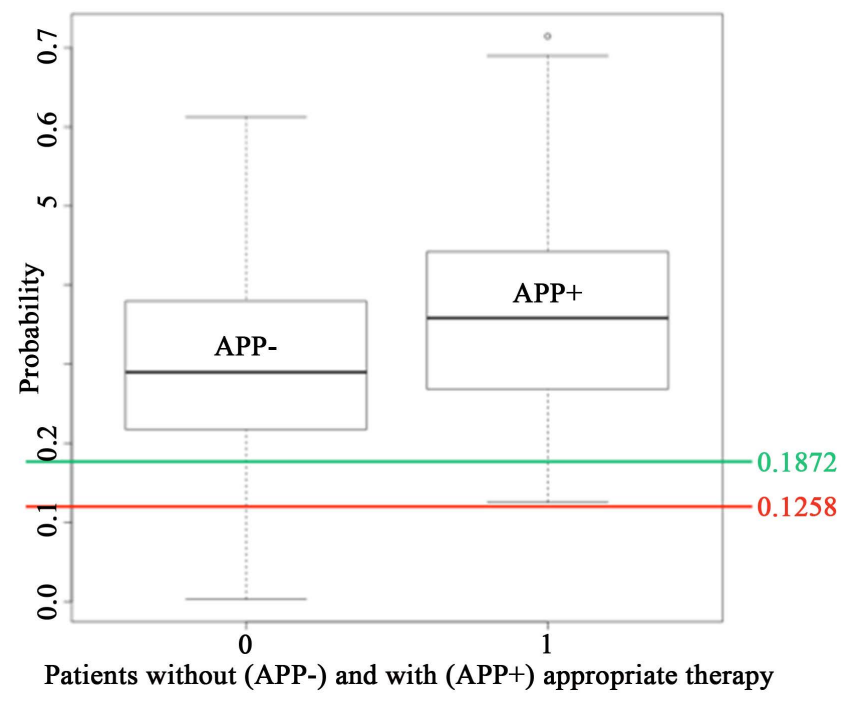

Figure 2. SCD risk in patients with (APP+) and without (APP-) appropriate therapy. 


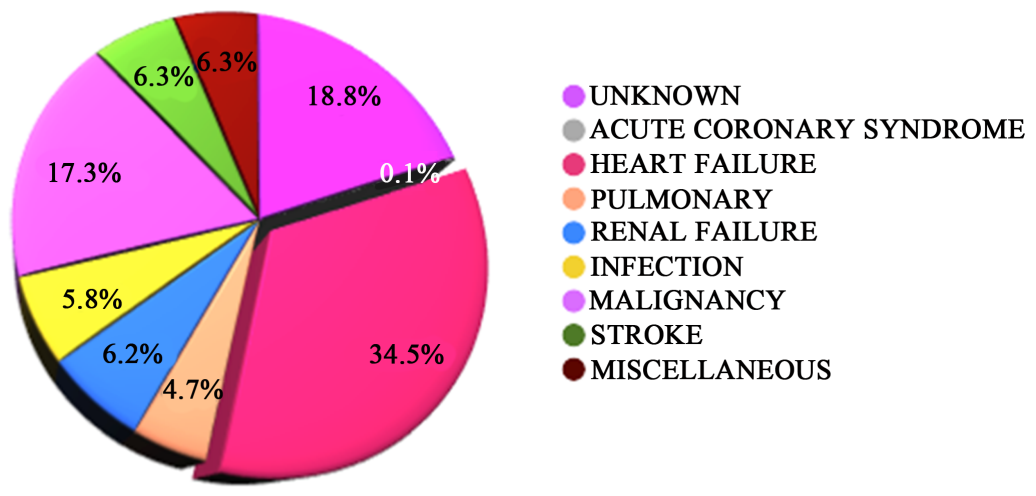

Figure 3. All causes mortality.

Table 3. Device-related complication including inappropriate shocks.

\begin{tabular}{cc}
\hline Types of complications & Patients (\%) \\
\hline Electrode dysfunction & $33(5.4)$ \\
Pocket-related (decubitus, hematoma) & $9(1.4)$ \\
Infection & $11(1.8)$ \\
Inappropriate shocks & $93(15.2)$ \\
Total number of patients with one or more complications \\
(including inappropriate shocks)
\end{tabular}

\section{Discussion}

Our study in a real-life cohort of primary prophylactic ICD-treated patients demonstrates that $8 \%$ of our patients annually receive presumably life-saving treatment for ventricular arrhythmias. This is almost the same proportion of patients as seen in the MADIT II [21], DEFINITE [22], and SCD-Heft [23] studies. The follow-up time in our study was also relatively long and complication rates increased over time. In our population, $22.5 \%$ of patients population had complications, including $15.2 \%$ of patients that received inappropriate therapies, principally caused by supraventricular arrhythmia. The main reason for inappropriate therapy in our study, as in many others [12] [24] [25], was atrial fibrillation. Better knowledge and more 'conservative' programming (i.e. higher VT zones with longer detection intervals and more ATP therapy attempts before shock therapy) may have contributed to the reduced number of unnecessary shocks [26]. However, no complications in our study were lethal and there was no association between complications and increased mortality.

This study demonstrates that baseline characteristics of ICD recipients can be useful for identifying patients at high risk for appropriate therapies and that these parameters are different according to their type of cardiomyopathy. Atrial fibrillation, NYHA class III-IV, comorbidities such as vasculopathy and diabetes, hyponatremia, may be interpreted as an epiphenomenon or as a surrogate of advanced heart failure that leads to more ICD therapies. Other previously described predictors for ICD therapies were not confirmed by our findings, as renal dysfunction [9], age [10] and gender [11] [12]. This could be explained by the 
fact that we included a homogenous population and optimal medical therapy prior to reference in our tertiary centre. Renal dysfunction, obesity and advanced age were not as prevalent in our study population as in other studies and thus failed to reach a significant predictive value.

Our logistic regression using seven clinical parameters-atrial fibrillation, diabetes, vasculopathy, NYHA class, left atrial diameter, ejection fraction, natremia-identified a population with a higher risk of appropriate therapy.

Using a cut off of probability $<0.1872$ we identified a population at low SCD risk: only $9.8 \%$ patient had appropriate ICD therapy during the follow-up (about $2.45 \%$ per year) and the ICD treatment was only on sustained VT (in most cases only one ATP was necessary). Excluding these population we could have avoided ICD implantation in about $15 \%$ that is a significant number on a large scale. Only few patients under this threshold received appropriate therapy, but only on one episode of VT.

If we considered a less tighten cut off including all patient that received appropriate therapy, we were sure not to lose any patient because of SCD: a probability $<0.1258$ identifies a subgroup at a very low risk (without any ICD therapy) and so we should potentially reduce implantation of $10 \%$. It is an easy score because it is based on clinical features that are routinely evaluated before implantation. Obviously, before extended clinical implementation, it could be important to test this score on a larger population to confirm accuracy and reproducibility. These findings reveal the most important predictors of ICD therapies in a realworld experience and are valuable for their ease use in clinical practice.

\section{Limitations}

This is not a randomized clinical trial but a retrospective study based on the detailed analysis of medical records from patients with primary preventive ICD treatment in a long period of follow up. However, during the last 10 years, there were not so many change in primary prevention indications and pharmacological treatment. This is a single-centre study with the limitations of a post hoc analysis. However, we included consecutive enrolled patients with regular and thorough device interrogations to obtain a comprehensive dataset.

\section{Conclusion}

In our real-life population of primary prevention ICD patients ventricular arrhythmias necessitating ICD therapy are common ( $8 \%$ annually), but complications are frequent ( $4 \%$ annually). Comorbidities, echo parameters, laboratory tests and functional class should be taken into consideration for a better selection of population candidate to ICD therapy, to reduce ineffective implantation. Our proposed score may eventually reduce from $10 \%$ to $15 \%$ future ICD implantation.

\section{References}

[1] Zipes, D.P., Camm, A.J., Borggrefe, M., Buxton, A.E., Chaitman, B., Fromer, M., 
Gregoratos, G., Klein, G., Moss, A.J., Myerburg, R.J., Priori, S.G., Quinones, M.A., Roden, D.M., Silka, M.J., Tracy, C., Priori, S.G., Blanc, J.J., Budaj, A., Camm, A.J., Dean, V., Deckers, J.W., Despres, C., Dickstein, K., Lekakis, J., McGregor, K., Metra, M., Morais, J., Osterspey, A., Tamargo, J.L., Zamorano, J.L., Smith Jr., S.C., Jacobs, A.K., Adams, C.D., Antman, E.M., Anderson, J.L., Hunt, S.A., Halperin, J.L., Nishimura, R., Ornato, J.P., Page, R.L. aand Riegel, B. (2006) ACC/AHA/ESC 2006 Guidelines for Management of Patients with Ventricular Arrhythmias and the Prevention of Sudden Cardiac Death: A Report of the American College of Cardiology/American Heart Association Task Force and the European Society of Cardiology Committee for Practice Guidelines (Writing Committee to Develop Guidelines for Management of Patients with Ventricular Arrhythmias and the Prevention of Sudden Cardiac Death) Developed in collaboration with the European Heart Rhythm Association and the Heart Rhythm Society. Europace, 8, 746-837.

https://doi.org/10.1093/europace/eul108

[2] Priori, S.G., Blomstrom-Lundqvist, C., Mazzanti, A., Blom, N., Borggrefe, M., Camm, J., Elliott, P.M., Fitzsimons, D., Hatala, R., Hindricks, G., Kirchhof, P., Kjeldsen, K., Kuck, K.H., Hernandez-Madrid, A., Nikolaou, N., Norekval, T.M., Spaulding, C. and Van Veldhuisen, D.J. (2015) 2015 ESC Guidelines for the Management of Patients with Ventricular Arrhythmias and the Prevention of Sudden Cardiac Death: The Task Force for the Management of Patients with Ventricular Arrhythmias and the Prevention of Sudden Cardiac Death of the European Society of Cardiology (ESC) Endorsed by: Association for European Paediatric and Congenital Cardiology (AEPC). European Heart Journal, 36, 2793-2867.

https://doi.org/10.1093/eurheartj/ehv316

[3] Nanthakumar, K., Epstein, A.E., Kay, G.N., Plumb, V.J. and Lee, D.S. (2004) Prophylactic Implantable Cardioverter-Defibrillator Therapy in Patients with Left Ventricular Systolic Dysfunction: A Pooled Analysis of 10 Primary Prevention Trials. Journal of the American College of Cardiology, 44, 2166-2172. https://doi.org/10.1016/j.jacc.2004.08.054

[4] Smith, T., Jordaens, L., Theuns, D.A., van Dessel, P.F., Wilde, A.A. and Hunink, M.G. (2013) The Cost-Effectiveness of Primary Prophylactic Implantable Defibrillator Therapy in Patients with Ischaemic or Non-Ischaemic Heart Disease: A European Analysis. European Heart Journal, 34, 211-219.

https://doi.org/10.1093/eurheartj/ehs090

[5] van Rees, J.B., Borleffs, C.J., de Bie, M.K., Stijnen, T., van Erven, L., Bax, J.J. and Schalij, M.J. (2011) Inappropriate Implantable Cardioverter-Defibrillator Shocks: Incidence, Predictors, and Impact on Mortality. Journal of the American College of Cardiology, 57, 556-562. https://doi.org/10.1016/j.jacc.2010.06.059

[6] Alter, P., Waldhans, S., Plachta, E., Moosdorf, R. and Grimm, W. (2005) Complications of Implantable Cardioverter Defibrillator Therapy in 440 Consecutive Patients. Pacing and Clinical Electrophysiology: Pacing and Clinical Electrophysiolo$g y$, 28, 926-932. https://doi.org/10.1111/j.1540-8159.2005.00195.x

[7] Borleffs, C.J., van Rees, J.B., van Welsenes, G.H., van der Velde, E.T., van Erven, L., Bax, J.J. and Schalij, M.J. (2010) Prognostic Importance of Atrial Fibrillation in Implantable Cardioverter-Defibrillator Patients. Journal of the American College of Cardiology, 55, 879-885. https://doi.org/10.1016/j.jacc.2009.09.053

[8] Smit, M.D., Van Dessel, P.F., Rienstra, M., Nieuwland, W., Wiesfeld, A.C., Tan, E. S., Anthonio, R.L., Van Veldhuisen, D.J. and Van Gelder, I.C. (2006) Atrial Fibrillation Predicts Appropriate Shocks in Primary Prevention Implantable Cardioverter-Defibrillator Patients. Europace, 8, 566-572. https://doi.org/10.1093/europace/eul081 
[9] Takahashi, A., Shiga, T., Shoda, M., Manaka, T., Ejima, K. and Hagiwara, N. (2009) Impact of Renal Dysfunction on Appropriate Therapy in Implantable Cardioverter Defibrillator Patients with Non-Ischaemic Dilated Cardiomyopathy. Europace, 11, 1476-1482. https://doi.org/10.1093/europace/eup210

[10] Bruch, C., Bruch, C., Sindermann, J., Breithardt, G. and Gradaus, R. (2007) Prevalence and Prognostic Impact of Comorbidities in Heart Failure Patients with Implantable Cardioverter-Defibrillator. Europace, 9, 681-686.

https://doi.org/10.1093/europace/eum097

[11] Saxon, L.A., Bristow, M.R., Boehmer, J., Krueger, S., Kass, D.A., De Marco, T., Carson, P., DiCarlo, L., Feldman, A.M., Galle, E. and Ecklund, F. (2006) Predictors of Sudden Cardiac Death and Appropriate Shock in the Comparison of Medical Therapy, Pacing, and Defibrillation in Heart Failure (COMPANION) Trial. Circulation, 114, 2766-2772. https://doi.org/10.1161/CIRCULATIONAHA.106.642892

[12] Sjoblom, J., Kalm, T., Gadler, F., Ljung, L., Frykman, V., Rosenqvist, M., Platonov, P. and Borgquist, R. (2015) Efficacy of Primary Preventive ICD Therapy in an Unselected Population of Patients with Reduced Left Ventricular Ejection Fraction. Europace, 17, 255-261. https://doi.org/10.1093/europace/euu219

[13] Dizon, J., Chen, K., Dizon, S., Biviano, A., Whang, W., Ehlert, F., Vazquez, J., Nazif, T. and Garan, H. (2011) A Comparison of Long-Standing Implantable Cardioverter-Defibrillator Patients with and without Appropriate Therapy for Ventricular Arrhythmias: Impact of a Widening QRS. Europace, 13, 77-81.

https://doi.org/10.1093/europace/euq363

[14] Lang, R.M., Bierig, M., Devereux, R.B., Flachskampf, F.A., Foster, E., Pellikka, P.A., Picard, M.H., Roman, M.J., Seward, J., Shanewise, J., Solomon, S., Spencer, K.T., St John Sutton, M., Stewart, W. (2006) Recommendations for Chamber Quantification. European Heart Journal-Cardiovascular Imaging, 7, 79-108. https://doi.org/10.1016/j.euje.2005.12.014

[15] Nagueh, S.F., Appleton, C.P., Gillebert, T.C., Marino, P.N., Oh, J.K., Smiseth, O.A., Waggoner, A.D., Flachskampf, F.A., Pellikka, P.A. and Evangelisa, A. (2009) Recommendations for the Evaluation of Left Ventricular Diastolic Function by Echocardiography. European Heart Journal-Cardiovascular Imaging, 10, 165-193. https://doi.org/10.1093/ejechocard/jep007

[16] Quinones, M.A., Otto, C.M., Stoddard, M., Waggoner, A. and Zoghbi, W.A. (2002) Recommendations for Quantification of Doppler Echocardiography: A Report from the Doppler Quantification Task Force of the Nomenclature and Standards Committee of the American Society of Echocardiography. Journal of the American Society of Echocardiography, 15, 167-184. https://doi.org/10.1067/mje.2002.120202

[17] Green, C.P., Porter, C.B., Bresnahan, D.R. and Spertus, J.A. (2000) Development and Evaluation of the Kansas City Cardiomyopathy Questionnaire: A New Health Status Measure for Heart Failure. Journal of the American College of Cardiology, 35, 1245-1255. https://doi.org/10.1016/S0735-1097(00)00531-3

[18] Rector, T.S. and Cohn, J.N. (1992) Assessment of Patient Outcome with the Minnesota Living with Heart Failure Questionnaire: Reliability and Validity during a Randomized, Double-Blind, Placebo-Controlled Trial of Pimobendan. American Heart Journal, 124, 1017-1025. https://doi.org/10.1016/0002-8703(92)90986-6

[19] American Thoracic Society (2002) ATS Statement: Guidelines for the Six-Minute Walk Test. American Journal of Respiratory and Critical Care Medicine, 166, 111 117. https://doi.org/10.1164/ajrccm.166.1.at1102

[20] Akaike, H. (1974) A New Look at the Statistical Model Identification. IEEE Transactions on Automatic Control, 19, 716-723. 
https://doi.org/10.1109/TAC.1974.1100705

[21] Moss, A.J., Zareba, W., Hall, W.J., Klein, H., Wilber, D.J., Cannom, D.S., Daubert, J.P., Higgins, S.L., Brown, M.W, and Andrews, M.L. for the Multicenter Automatic Defibrillator Implantation Trial II Investigators (2002) Prophylactic Implantation of a Defibrillator in Patients with Myocardial Infarction and Reduced Ejection Fraction. The New England Journal of Medicine, 346, 877-883. https://doi.org/10.1056/NEJMoa013474

[22] Kadish, A., Dyer, A., Daubert, J.P., Quigg, R., Estes, N.A., Anderson, K.P., Calkins, H., Hoch, D., Goldberger, J., Shalaby, A., Sanders, W.E., Schaechter, A. and Levine, J.H., for the Defibrillators in Non-Ischemic Cardiomyopathy Treatment Evaluation (DEFINITE) Investigators (2004) Prophylactic Defibrillator Implantation in $\mathrm{Pa}$ tients with Nonischemic Dilated Cardiomyopathy. The New England Journal of Medicine, 350, 2151-2158. https://doi.org/10.1056/NEJMoa033088

[23] Bardy, G.H., Lee, K.L., Mark, D.B., Poole, J.E., Packer, D.L., Boineau, R., Domanski, M., Troutman, C., Anderson, J., Johnson, G., McNulty, S.E., Clapp-Channing, N., Davidson-Ray, L.D., Fraulo, E.S., Fishbein, D.P., Luceri, R.M. and Ip, J.H. for the Sudden Cardiac Death in Heart Failure Trial (SCD-HeFT) Investigators (2005) Amiodarone or an Implantable Cardioverter-Defibrillator for Congestive Heart Failure. The New England Journal of Medicine, 352, 225-237. https://doi.org/10.1056/NEJMoa043399

[24] Daubert, J.P., Zareba, W., Cannom, D.S., McNitt, S., Rosero, S.Z., Wang, P., Schuger, C., Steinberg, J.S., Higgins, S.L., Wilber, D.J., Klein, H., Andrews, M.L., Hall, W.J. and Moss, A.J. (2008) Inappropriate Implantable Cardioverter-Defibrillator Shocks in MADIT II: Frequency, Mechanisms, Predictors, And survival Impact. Journal of the American College of Cardiology, 51, 1357-1365. https://doi.org/10.1016/j.jacc.2007.09.073

[25] Rosenqvist, M., Beyer, T., Block, M., den Dulk, K., Minten, J. and Lindemans, F. (1998) Adverse Events with Transvenous Implantable Cardioverter-Defibrillators: A Prospective Multicenter Study. Circulation, 98, 663-670. https://doi.org/10.1161/01.CIR.98.7.663

[26] Brignole, M., Auricchio, A., Baron-Esquivias, G., Bordachar, P., Boriani, G., Breithardt, O.A., Cleland, J., Deharo, J.C., Delgado, V., Elliott, P.M., Gorenek, B., Israel, C.W., Leclercq, C., Linde, C., Mont, L., Padeletti, L., Sutton, R., Vardas, P.E., ESC Committee for Practice Guidelines (CPG), Zamorano, J. L., Achenbach, S., Baumgartner, H., Bax, J.J., Bueno, H., Dean, V., Deaton, C., Erol, C., Fagard, R., Ferrari, R., Hasdai, D., Hoes, A.W., Kirchhof, P., Knuuti, J., Kolh, P., Lancellotti, P., Linhart, A., Nihoyannopoulos, P., Piepoli, M.F., Ponikowski, P., Sirnes, P.A., Tamargo, J.L., Tendera, M., Torbicki, A., Wijns, W., Windecker, S., Document, R., Kirchhof, P., Blomstrom-Lundqvist, C., Badano, L.P., Aliyev, F., Bansch, D., Baumgartner, H., Bsata, W., Buser, P., Charron, P., Daubert, J.C., Dobreanu, D., Faerestrand, S., Hasdai, D., Hoes, A.W., Le Heuzey, J.Y., Mavrakis, H., McDonagh, T., Merino, J.L., Nawar, M.M., Nielsen, J.C., Pieske, B., Poposka, L., Ruschitzka, F., Tendera, M., Van Gelder, I.C. and Wilson, C.M. (2013) 2013 ESC Guidelines on Cardiac Pacing and Cardiac Resynchronization Therapy: The Task Force on Cardiac Pacing and Resynchronization Therapy of the European Society of Cardiology (ESC). Developed in Collaboration with the European Heart Rhythm Association (EHRA). European Heart Journal, 34, 2281-2329. https://doi.org/10.1093/eurheartj/eht150 
Submit or recommend next manuscript to SCIRP and we will provide best service for you:

Accepting pre-submission inquiries through Email, Facebook, LinkedIn, Twitter, etc. A wide selection of journals (inclusive of 9 subjects, more than 200 journals)

Providing 24-hour high-quality service

User-friendly online submission system

Fair and swift peer-review system

Efficient typesetting and proofreading procedure

Display of the result of downloads and visits, as well as the number of cited articles Maximum dissemination of your research work

Submit your manuscript at: http://papersubmission.scirp.org/

Or contact wicd@scirp.org 